\title{
Reducing risk of childhood obesity in the wake of covid-19
}

\author{
Alexandra Chung and colleagues call for governments to prioritise child obesity as they \\ implement measures to recover from the pandemic
}

T he swift and necessary public health response to the covid-19 pandemic has had detrimental consequences for the prevention and management of childhood obesity, a concern critically in need of public health action. Although children are not as severely affected by covid-19 as adultsexperiencing fewer or no symptoms-the public health response to mitigate its spread has exacerbated several risk factors for childhood obesity. Extended lockdowns and social distancing measures have increased children's exposure to obesogenic environments and disrupted their participation in health promoting behaviours. ${ }^{1}$

Childhood obesity affects an estimated 50 million girls and 74 million boys worldwide. ${ }^{2}$ These children are at greater risk of developing related functional, metabolic, and psychological conditions; experiencing pervasive weight bias and stigma; and having greater healthcare costs. Childhood obesity is strongly correlated with risk of adult obesity and poor health, with considerable social and economic consequences. ${ }^{34}$ Despite efforts, no country is on track to meet the targets set out by the World Health Organization's Commission on Ending Childhood Obesity (ECHO). ${ }^{5}$

All children have a right to healthcare, yet the evidence is clear that current

\section{REY MESSAGES}

- The public health response to covid19 has exacerbated risk factors for the development and progression of childhood obesity

- An opportunity exists to leverage the global attention brought about by covid-19 for public health action to improve population health

- Action to reduce childhood obesity must be equitable, evidence based, and government led

- Priorities include promotion of healthy school food and physical activity environments, reducing exposure to unhealthy food marketing, and taxation of sugar sweetened beverages obesogenic environments are detrimental to health, violating the UN Convention on the Rights of the Child, to which many countries are signatories. ${ }^{6}$ Furthermore, childhood obesity is greater among poorer children, and trends continue to rise among marginalised and deprived populations, and those in low and middle income countries. $^{2}$ The impact of covid-19 might exacerbate these inequities, with data from the United States indicating widening racial, ethnic, and neighbourhood socioeconomic differences in childhood

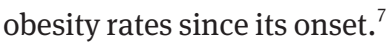

As we look towards recovery from covid19 , we have the chance to build back better, with the opportunity for increased focus on the role of public health and prevention to protect and promote the health of populations. With the public health response to covid-19 exacerbating risk factors for childhood obesity, there is an increased urgency for evidence based action.

We highlight the effect of the public health response to covid-19 on risk factors for childhood obesity and discuss evidence based action across three key areas: providing healthy food and physical activity environments for preschool and school age children; reducing children's exposure to unhealthy food marketing; and imposing an effective tax on sugar sweetened beverages. These actions are outlined in WHO commission's recommendations to prevent the development of obesity among infants, children, and adolescents. ${ }^{5}$ International evidence suggests that they are effective, equitable, and cost effective in improving diets and thus reducing obesity among children. ${ }^{89}$ Although much of the evidence to date is drawn from high income countries, these approaches have been identified as double duty actions, simultaneously dealing with the common drivers of overweight, obesity, and undernutrition across countries of all levels of development. ${ }^{10}$

\section{Healthy school food and physical activity environments}

As part of government efforts to reduce the spread of covid-19, schools and early childhood education and care settings have sometimes been closed for long periods. More than one year into the pandemic, school closures continue for millions of children worldwide. ${ }^{11}$ As a consequence, many schools have turned to home learning, with reduced opportunities for physical activity and a reliance on screens for education and communication. ${ }^{12-14}$ Excess sedentary time and inadequate physical activity are known risk factors for the development of childhood obesity.

School closures have also reduced the availability of nutritious foods. Data from the US indicate that many children rely on food provided by school and nurseries for up to two thirds of daily dietary needs. ${ }^{15}$ Without these programmes during school closures or holidays, children miss a vital source of nutrition for healthy growth and development and are at increased risk of food insecurity and health inequities.

Fast food chains have indicated their willingness to replace missed meals during school closures. For example, in the United Kingdom McDonald's announced it would provide one million free meals during the October school holidays. ${ }^{16}$ The provision of school meals by the fast food industry is not a suitable alternative to government policy and might increase children's consumption of unhealthy food and beverages.

Recognising that covid-19 restrictions differ between countries and have been periodically lifted and reinstated, early childhood and school settings have a dual role: to help children to eat well and be physically active at home; and as children return to campus, provide nutritious food and drinks and physical education curriculums. Box 1 provides a case study of a US school food policy.

\section{Marketing of unhealthy foods and non- alcoholic beverages to children}

A further consequence of covid-19 restrictions has been an increased reliance on digital platforms for children's learning and communication. Screen time increases exposure to unhealthy food and beverage marketing. Evidence consistently shows that marketing unhealthy foods and beverages impairs children's dietary preferences 
Box 1: Case study-the Healthy, HungerFree Kids Act

The Healthy, Hunger-Free Kids Act of 2010 improved nutrition standards for meals and beverages provided through the US National School Lunch, Breakfast, and Smart Snacks Programs, reaching 50 million children across 99000 schools. This policy, championed by first lady Michelle Obama, improved the nutritional quality of school meals and was associated with substantial reductions in obesity rates among children from low income households. ${ }^{17}$ Findings indicate that improved nutrition standards in school meal programmes are likely to equitably improve children's diet related health.

and consumption. ${ }^{18}$ Research from many countries has also found that children from minority and socioeconomically disadvantaged backgrounds are disproportionately exposed to such marketing. ${ }^{19}$

Despite this, or perhaps because of it, food and beverage industries have seized the opportunity to turn covid-19 into a new marketing strategy, with stay at home messaging and the promotion of home delivery or drive through services prominent features of advertising. ${ }^{20}$ Industries also promoted their donations of fast food and confectionery to frontline workers throughout the pandemic. These strategies show opportunism by an industry that that cannot self-regulate effectively and places profits ahead of public health.

Actions by the food and beverage industry pose key challenges to government policies to restrict marketing of unhealthy food and beverages to children. ${ }^{21}$ Policy development and its introduction require strong political will. Guidance has been outlined by WHO, including recommendations for regulation that restricts all forms of marketing of unhealthy food and beverages. ${ }^{22}$ Box 2 provides examples from the UK.

\section{Tax on sugar sweetened beverages}

In many regions, covid-19 has changed the way people eat. Parents are reporting changes in their children's dietary behaviour, including more frequent snacking, the use of food for pleasure and comfort, and increased consumption of unhealthy food and sugary drinks. ${ }^{1425}$ Parents are also reporting enhanced levels of covid-19 related stress, and this has been associated with children's intake of unhealthy snacks. ${ }^{26}$ Meanwhile, household budgets
Box 2: Case study: London public transport ban on unhealthy food advertising

A ban on unhealthy food advertising across London's public transport network was implemented in February 2019. The advertising policy restricts the promotion of food and non-alcoholic drinks that are high in fat, salt, or sugar on all services operated or regulated by Transport for London, reducing public exposure to marketing of unhealthy food. Factors deemed critical to the successful adoption of this policy include strong political will from the mayor of London; effective government partnerships between the Greater London Authority and Transport for London; support from London boroughs; policy alignment with local government policies on sugar reduction and healthier foods; and integration of the advertising policy within the broader London food strategy. ${ }^{23}$

In June 2021, the UK prime minister announced plans for a ban on advertising of food and drinks that are high in fat, salt, or sugar across all forms of digital media and before $9 \mathrm{pm}$ on television. The ban is due to come into effect in $2023 .^{24}$

are under pressure from rising unemployment and economic recession. ${ }^{27}$ These factors might increase the appeal of low cost, shelf stable, processed food and beverages. For socially and economically vulnerable families, the economic and employment effects of covid-19 will probably be more severe and lasting. ${ }^{28}$

A tax on sugar sweetened beverages is an effective public health intervention that can improve health equity. Evidence strongly suggests that reductions in consumption of sugar sweetened beverages will lead to reduced excess weight gain and reduced obesity. ${ }^{29}$ Evidence also indicates that a tax on these beverages is an equitable intervention, with health benefits reported to be either similar or greater for those at socioeconomic disadvantage. ${ }^{30}$ Real world evaluations have shown that an excise tax on sugar sweetened beverages is effective in reducing both purchase and consumption. ${ }^{31}$ A recent meta-analysis of such taxes across the Americas records these effects. ${ }^{32}$ Data from the UK show that taxes incentivise industry to reduce sugar content through reformulation. ${ }^{334}$ Studies indicate that excise taxes on sugar sweetened beverages are cost effective, saving more money in future healthcare expenses than the projected cost of implementation. ${ }^{835}$ Revenue generated by the tax can also be spent on public health.

As the number of jurisdictions introducing taxes on such beverages grows, evidence of their effect becomes increasingly available (box 3). The dominant challenge is opposition from the beverage industry. To overcome this requires robust design of a tax that is relevant to the local context, underpinned by evidence of local consumption of sugar sweetened beverages and associated health effects; the likely effect of the tax, including across socioeconomic groups; and projected use of revenue. ${ }^{37}$

\section{Conclusion}

The covid-19 pandemic has shown that governments can act swiftly to protect health and healthcare services. Leaders worldwide have gone to unprecedented lengths in the interest of public health during the covid-19 crisis, restricting societies in ways never witnessed by this generation. As a result, risk factors for the development and progression of childhood obesity have been exacerbated. As societies build back from covid-19, it is time to focus on childhood obesity risk factors amplified by the response, and to leverage growing support for public health action to promote population health. Priorities for action include promoting healthy school food and physical activity environments; reducing children's exposure to unhealthy food marketing; and imposing taxes on sugar sweetened beverages. These actions are successful, cost effective, can improve health equity, and contribute to a comprehensive approach to prevention of childhood obesity. The covid-19 pandemic presents an opportunity for governments worldwide to prioritise action as we rebuild economies and public health systems to deal with the problem of childhood obesity effectively and equitably.

Competing interests: We have read and understood BMJ policy on declaration of interests and have no relevant interests to declare.

Contributors and sources: All authors are fellows of the Salzburg Global Seminar Health and Health Care Innovation programme, "Halting the Childhood Obesity Epidemic: Identifying Decisive Interventions in Complex Systems," convened in Salzburg, Austria on 14-19 December 2019. This article stems from discussions that began during our deliberations and interactions in Austria and have continued to evolve in the context of the covid-19 global pandemic. All authors worked together to conceptualise this article. AC and LT drafted the article and all authors contributed to revisions and approved the final version of the manuscript. $A C$ is the guarantor.

Provenance and peer review: Commissioned; externally peer reviewed. 


\section{Box 3: Case studies}

\section{UK soft drinks industry levy}

In the UK, a two tier soft drink levy was announced in March 2016 and introduced in April 2018. The initiative was explicitly designed to incentivise product reformulation, with the levy targeted towards soft drink manufacturers rather than consumers. Drinks with $\geq 8 \mathrm{~g}$ sugar $/ 100$ $\mathrm{mL}$ (high tier) are taxed at $f 0.24 / \mathrm{L}$ and drinks with $\geq 5$ to $<8 \mathrm{~g}$ sugar $/ 100 \mathrm{~mL}$ (low tier) are taxed at $f 0.18 / \mathrm{L}$. Drinks with $<5 \mathrm{~g}$ sugar $/ 100 \mathrm{~mL}$ are not taxed.

Evaluations found that the volume of drinks purchased, and sugar content in drinks decreased after implementation of the levy for high and low tier drink categories. Purchase of untaxed drinks, however, increased. For all soft drink categories combined, the overall volume purchased remained unchanged, but the amount of sugar purchased decreased by $30 \mathrm{~g}$ per household per week. ${ }^{33}$

\section{Mexico excise tax on sugar sweetened beverages}

In Mexico, an excise tax of 1 peso per litre on sugar sweetened beverages was introduced in January 2014. During the two years after its introduction, evaluation of household purchases showed an average decline of $7.6 \%$ for taxed beverages and a $2.1 \%$ increase in purchases of untaxed beverages. Reductions in purchases of taxed beverages were seen for households across all socioeconomic levels but were greatest among lowest socioeconomic households. ${ }^{36}$

The tax on sugar sweetened beverages in Mexico is projected to prevent 239900 instances of obesity, of which almost $40 \%$ would be among children. Furthermore, the tax is estimated to save $\$ 3.98$ ( $f 2.88$; $€ 3.37$ ) in healthcare costs for each dollar spent on implementation. Modelling suggests that doubling the tax to 2 pesos per litre would nearly double the health benefits and cost savings. ${ }^{35}$

This article is part of a series from the Salzburg Global Seminar on building healthy communities: healthy children, healthy weight. Open access fees were funded by the Robert Wood Johnson Foundation. The BMJ peer reviewed, edited, and made the decision to publish the article with no involvement from the foundation.

Alexandra Chung, research fellow ${ }^{1,2}$

Louise Tully, PhD scholar ${ }^{3}$

Sarah Czernin, research assistant ${ }^{4}$

Rachel Thompson, policy adviser ${ }^{5}$

Athar Mansoor, PhD candidate in public policy ${ }^{6}$

Steven L Gortmaker, professor of the practice of health sociology

${ }^{1}$ Health and Social Care Unit, School of Public Health and Preventive Medicine, Monash University, Melbourne, Australia

${ }^{2}$ Global Obesity Centre (GLOBE), Institute for Health Transformation, Deakin University, Australia

${ }^{3}$ Obesity Research and Care Group, School of Physiotherapy, Royal College of Surgeons in Ireland University of Medicine and Health Sciences, Dublin, Ireland

${ }^{4}$ Austrian Academic Institute for Clinical Nutrition, Vienna, Austria

${ }^{5}$ World Obesity Federation, London, UK

${ }^{6}$ Division of Public Policy, Hong Kong University of Science and Technology, Hong Kong

${ }^{7}$ Department of Social and Behavioral Sciences, Harvard TH Chan School of Public Health, Boston, MA, USA

Correspondence to: AChung

alexandra.chung@monash.edu

\section{(i) (8)}

is is an Open Access article distributed in accordance with the Creative Commons Attribution Non Commercial (CC BY-NC 4.0) license, which permits others to distribute, remix, adapt, build upon this work non-commercially, and license their derivative works on different terms, provided the original work is properly cited and the use is non-commercial. See: http://creativecommons.org/ licenses/by-nc/4.0/.

\section{D) Check for updates}

1 Browne NT, Snethen JA, Greenberg CS, et al. When pandemics collide: the impact of covid-19 on childhood obesity. J Pediatr Nurs 2021;56:90-8 doi:10.1016/j.pedn.2020.11.004

2 Abarca-Gómez L, Abdeen ZA, Hamid ZA, et al, NCD Risk Factor Collaboration (NCD-RisC). Worldwide trends in body-mass index, underweight, overweight, and obesity from 1975 to 2016: a pooled analysis of 2416 population based measurement studies in 128.9 million children, adolescents, and adults. Lancet 2017;390:2627-42. doi:10.1016/S01406736(17)32129-3

3 Hamilton D, Dee A, Perry IJ. The lifetime costs of overweight and obesity in childhood and adolescence: a systematic review. Obes Rev 2018;19:452-63. doi:10.1111/obr.12649

4 OECD. The heavy burden of obesity . 2019. https:// www.oecd.org/health/health-systems/Heavyburden-of-obesity-Policy-Brief-2019.pdf

5 World Health Organization. Report of the commission on ending childhood obesity. World Health Organization, 2016. https://apps.who.int/iris/bitstream/ handle/10665/204176/9789241510066_eng. pdf?sequence $=1$

6 United Nations. United Nations Convention on the Rights of the Child. https://www.unicef.org.uk/whatwe-do/un-convention-child-rights/

7 Jenssen BP, Kelly MK, Powell M, Bouchelle Z, Mayne SL, Fiks AG. COVID-19 and changes in child obesity. Pediatrics 2021;147:e2021050123. doi:10.1542/ peds.2021-050123

8 Gortmaker SL, Wang YC, Long MW, et al. Three interventions that reduce childhood obesity are projected to save more than they cost to implement. Health Aff (Millwood) 2015;34:1932-9. doi:10.1377/hlthaff.2015.0631

9 Kumanyika S. Getting to equity in obesity prevention: a new framework. National Academy of Medicine,
2017. https://nam.edu/getting-to-equity-in-obesityprevention-a-new-framework/

10 Hawkes C, Ruel MT, Salm L, Sinclair B, Branca F. Double-duty actions: seizing programme and policy opportunities to address malnutrition in all its forms. Lancet 2020;395:142-55. doi:10.1016/S01406736(19)32506-1

11 United Nations Educational Scientific and Cultural Organization (UNESCO). https://en.unesco.org/ covid19/educationresponse.

12 Nagata JM, Abdel Magid HS, Pettee Gabriel K. Screen time for children and adolescents during the COVID-19 pandemic. Obesity (Silver Spring) 2020;28:1582-3. doi:10.1002/oby.22917

13 Douglas M, Katikireddi SV, Taulbut M, McKee M, McCartney G. Mitigating the wider health effects of covid-19 pandemic response. BMJ 2020;369:m1557. doi:10.1136/bmj.m1557

14 Pietrobelli A, Pecoraro L, Ferruzzi A, et al. Effects of COVID-19 lockdown on lifestyle behaviors in children with obesity living in Verona, Italy: a longitudinal study. Obesity (Silver Spring) 2020;28:1382-5. doi:10.1002/oby. 22861

15 Dunn CG, Kenney E, Fleischhacker SE, Bleich SN. Feeding low-income children during the covid-19 pandemic. N EnglJ Med 2020;382:e40. doi:10.1056/NEJMp2005638

16 Dean G. McDonald's is offering a million free meals to in-need UK children as part of footballer Marcus Rashford's campaign against food poverty. Business Insider 2020 Oct 23.

17 Kenney EL, Barrett JL, Bleich SN, Ward ZJ, Cradock AL, Gortmaker SL. Impact of the Healthy, Hunger-Free Kids Act on obesity trends: study examines impact of the Healthy, Hunger-Free Kids Act of 2010 on childhood obesity trends. J Health Aff 2020;39:1122 9. doi:10.1377/hlthaff.2020.00133

18 Smith R, Kelly B, Yeatman H, Boyland E. Food marketing influences children's attitudes, preferences and consumption: a systematic critical review. Nutrients 2019;11:875. doi:10.3390/ nu11040875

19 Backholer K, Gupta A, Zorbas C, et al. Differential exposure to, and potential impact of, unhealthy advertising to children by socio-economic and ethnic groups: a systematic review of the evidence. Obes Rev 2021:22:e13144. doi:10.1111/obr.13144

20 White M, Nieto C, Barquera S. Good deeds and cheap marketing-the food industry in the times of COVID-19. Obesity (Silver Spring) 2020;28:1578-9. doi:10.1002/oby. 22910

21 World Cancer Research Fund. Building Momentum: a series of reports providing an overview of lessons on implementing evidence-informed nutrition policy London: World Cancer Research Fund International; 2020 https://www.wcrf.org/int/latest/news-updates/ building-momentum-series-reports-providingoverview-lessons-implementing.

22 World Health Organization. Set of recommendations on the marketing of foods and non-alcoholic beverages to children. Report No 9241500212 WHO, 2010. https://apps.who.int/iris/bitstream/ handle/10665/44416/9789241500210 eng.pdf

23 Halliday J, Platenkamp L, Nicolarea Y. A menu of actions to shape urban food environments for improved nutrition. GAIN, MUFPP and RUAF, 2019. https://www.gainhealth.org/resources/reports and-publications/menu-actions-shape-urban-foodenvironments-improved-nutrition

24 Sweney M. UK to ban junk food advertising online and before 9 pm on TV from 2023. Guardian 2021 Jun 23. https://www.theguardian.com/media/2021/ jun/23/uk-to-ban-junk-food-advertising-online-andbefore-9pm-on-tv-from-2023

25 Philippe K, Chabanet C, Issanchou S, MonneryPatris S. Child eating behaviors, parental feeding practices and food shopping motivations during the COVID-19 lockdown in France: (How) did they change?Appetite 2021;161:105132. doi:10.1016/j. appet.2021.105132 
26 Jansen E, Thapaliya G, Aghababian A, Sadler J, Smith K, Carnell S. Parental stress, food parenting practices and child snack intake during the COVID-19 pandemic. Appetite 2021;161:105119. doi:10.1016/j.appet.2021.105119

27 Hensher M. Covid-19, unemployment, and health: time for deeper solutions?BMJ 2020;371:m3687. doi:10.1136/bmj.m3687

28 Vargas ED, Sanchez GR. Covid-19 is having a devastating impact on the economic well-being of Latino families. Journal of Economics, Race and Policy 2020;3:262-9. https://link.springer.com/ article/10.1007/s41996-020-00071-0

29 Malik VS, Pan A, Willett WC, Hu FB. Sugar-sweetened beverages and weight gain in children and adults: a systematic review and meta-analysis. Am J Clin Nutr 2013;98:1084-102. doi:10.3945/ ajcn.113.058362

30 Backholer K, Sarink D, Beauchamp A, et al. The impact of a tax on sugar-sweetened beverages according to socio-economic position: a systematic review of the evidence. Public
Health Nutr 2016;19:3070-84. doi:10.1017/ S136898001600104X

31 Teng AM, Jones AC, Mizdrak A, Signal L, Genç M, Wilson N. Impact of sugar-sweetened beverage taxes on purchases and dietary intake: systematic review and meta-analysis. Obes Rev 2019;20:1187-204. doi:10.1111/obr.12868

32 Pan American Health Organization. Sugar-sweetened beverage taxation in the Region of the Americas. Washington, D.C.; 2020. Contract No.: License: CC BY-NC-SA 3.0 IGO. https://iris.paho.org/bitstream/ handle/10665.2/53252/9789275123003_eng. pdf? sequence $=1$ \&isAllowed $=y$

33 Pell D, Mytton O, Penney TL, et al. Changes in soft drinks purchased by British households associated with the UK soft drinks industry levy: controlled interrupted time series analysis. BMJ 2021;372:n254. doi:10.1136/bmj.n254

34 Scarborough P, Adhikari V, Harrington RA, et al. Impact of the announcement and implementation of the UK soft drinks industry levy on sugar content, price, product size and number of available soft drinks in the UK, 2015-19: a controlled interrupted time series analysis. PLOS Med 2020;17:e1003025. doi:10.1371/journal. pmed.1003025

35 Basto-Abreu A, Barrientos-Gutiérrez T, VidañaPérez D, et al. Cost-effectiveness of the sugarsweetened beverage excise tax In Mexico. Health Aff (Millwood) 2019;38:1824-31. doi:10.1377/ hlthaff.2018.05469

36 Colchero MA, Rivera-Dommarco J, Popkin BM, Ng SW. In Mexico, evidence of sustained consumer response two years after implementing a sugar-sweetened beverage tax. Health Aff (Millwood) 2017;36:56471. doi:10.1377/hlthaff.2016.1231

37 World Cancer Research Fund International. Building momentum: lessons on implementing a robust sugar sweetened beverage tax. 2018. https://www.wcrf. org/wp-content/uploads/2021/04/PPA-BuildingMomentum-Report-WEB.pdf

Cite this as: BMJ 2021;374:n1716

http://dx.doi.org/10.1136/bmj.n1716 